www.jmscr.igmpublication.org

Index Copernicus Value: 79.54

ISSN (e)-2347-176x ISSN (p) 2455-0450

crossrefDOI: https://dx.doi.org/10.18535/jmscr/v7i2.11

\title{
A Discussion of Superficial Temporal Space Infection of Odontogenic Origin In An Uncontrolled Diabetic Patient: A Case Report
}

\author{
Authors
}

\author{
Dr Arka Das ${ }^{1 *}$, Dr Anita R. Pal ${ }^{2}$, Dr Sunita R. Pal ${ }^{3}$
}

${ }^{1}$ Assistant Professor, M B KEDIA Dental College, Birgunj, Nepal

${ }^{2}$ Consultant, Oral \& Maxillofacial Surgeon, 32 Pearls Dental Care \& Cure Multi-speciality Hospital,

Navi Mumbai, Maharashtra-400708

${ }^{3}$ Post graduate, Department of Periodontology, Rajarajeswari Dental College and Hospital,

Bangalore-560074

*Corresponding Author

\section{Dr Arka Das}

Dept of Oral and Maxillofacial Surgery, MB Kedia Dental College, Birgunj, Nepal

Email: dr.arkadas@outlook.com, Tel: +917829483141,+9779826251195

\section{Abstract}

As described by Moore in 1975 The fascial spaces in head and neck are the potential spaces between the various layers of fascia normally filled with loose connective Tissue and bounded by anatomical barriers, usually of bone, muscle or fascial layers. Superficial temporal space is a secondary space. Diabetes mellitus is a metabolic disorder characterised by increase in blood glucose level. In diabetic patients there is decreased T Lymphocyte response, decreased neutrophil function, antioxidant system depression, glycosuria, lower secretion of inflammatory cytokines, hyperglycaemia which causes increased virulence of microorganism and apoptosis of PMNs all of which lead to increased chances and \or severity of infections. This paper highlights a case of superficial temporal space infection and buccal space infection of odontogenic origin in a patient of uncontrolled diabetes.

Keywords: Superficial temporal space, Odontogenic origin, Uncontrolled diabetes, Reduced mouth opening.

\section{Introduction}

The superficial temporal space lies in between the temporal fascia and the temporalis muscle. The temporalis fascia is a continuation of the parietidomasseteric fascia. The origin of the temporal fascia is zygomatic arch and terminates at the crest of the temporal bone. The extent or the boundaries of the superficial temporal space infection are, anteriorly the posterior surface of the lateral orbital rim, posterior border is at the junction of the temporal fascia and the pericranium at the posterior end of the temporalis muscle. The inferior border is demarcated by the zygomatic arch and the loose areolar connective present medially. At this place the superficial temporal space communicates with the submasseteric space. Around $2 \mathrm{~cm}$ above the zygomatic arch a small space is present which is formed because of the splitting of the temporal fascia which pass both medial and lateral to the zygomatic arch. Buccal space infections may follow the buccal fat pad into this space ${ }^{1}$. 
The contents of the superficial temporal space are Temporal fat pad, temporal branch of the facial nerve, the internal maxillary artery and its branches.

Neighbouring spaces from which infections can spread to the superficial temporal spaces are buccal, deep temporal and submasseteric spaces.

Pyogenic orofacial infections may originate in an odontogenic location. ${ }^{2}$ The majority are confined to local lesions, while in some cases they spread from the affected tooth along the anatomic spaces and occasionally advance to a site far from the initial infection. Significant morbidity or even death may occur in the cases that advance into the retropharyngeal, mediastinal, intra-cranial or intraorbital spaces. $^{3}$

This paper highlights a case of superficial temporal space infection and buccal space infection of odontogenic origin in a patient of uncontrolled diabetes.

\section{Case Report}

A 52 year old female patient visited the department with a complaint of severe pain and swelling in the left side of the face for the last 3 days along with inability to open her mouth since one day. Initially it was a small swelling that had started over the left middle third of the face. The swelling was accompanied by severe pain and low-grade fever. The swelling had increased in size over time. Patient had been taking over the counter painkillers for the pain for 3 days. The mouth opening was restricted since 1 day. As the OTC medicines did not reduce the pain patient reported to our centre. Patient on general physical examination gave no medical history but the patient was severely dehydrated and weak. On examination of the area of complaint there was a diffuse swelling present over the left middle third of the face and the left temporal region giving a dumbbell appearance of the swelling. Patient had a mouth opening of $5 \mathrm{~mm}$ and an orthopantogram (OPG) showed a root stump present with respect to the left maxillary second molar (27) and periodontally compromised maxillary left third molar (28). On routine blood investigation her random blood glucose was found to be $326 \mathrm{mg} / \mathrm{dl}$.

The patient was diagnosed with temporal and buccal space infection secondary to odontogenic abscess w.r.t. to left maxillary second and third molar $(27,28)$.

It was decided to do extraction of the two involved teeth and drain the buccal space and the superficial temporal space under local anaesthesia. Drainage was established through intraoral incision for the buccal space and extra oral incision superior to the zygomatic arch and drainage was secured using corrugated rubber drain

Once the incision and drainage was achieved was admitted and started on intravenous antibiotics and anti-inflammatory medications. Also on consultation with general physician patient was put on sliding scale insulin along with maintenance dose of RL and NS alternatively.

1 day post operative the swelling started reducing and on $3^{\text {rd }}$ post operativeday the mouth opening increased to around $15 \mathrm{~mm}$ from $5 \mathrm{~mm}$ preoperative.

Patient was discharged from the hospital on $3{ }^{\text {rd }}$ post operative day and kept under follow up for another two weeks. Patient was prescribed oral hypoglycaemic agents and advised to undergo treatment for her other infected teeth.

\section{Preoperative}

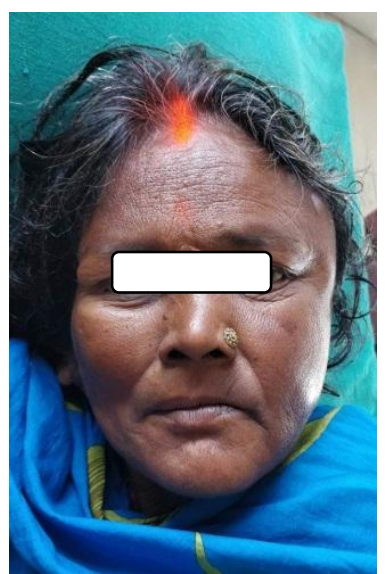

Figure 1: Swelling present in left temporal and mid face region 


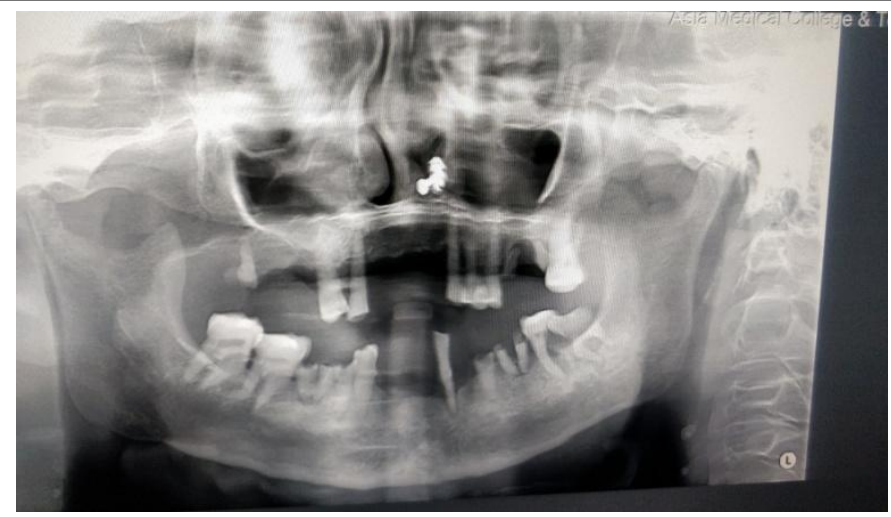

Figure 2 : OPG showing root stump in tooth no 27 and periodontally compromised 28

\section{Intra operative}

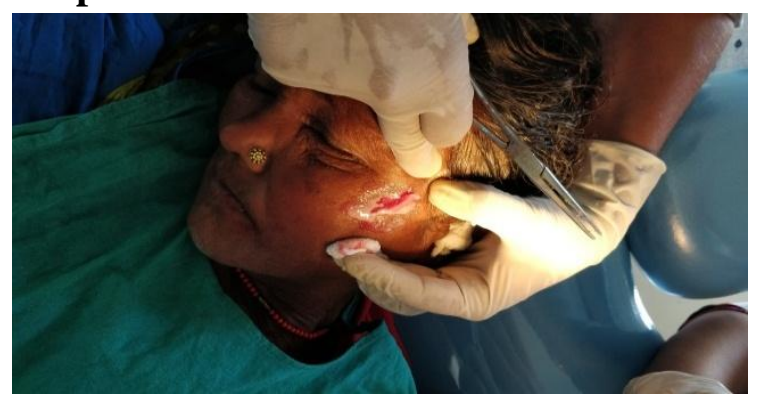

Figure 3: Extra oral incision placed superior to the zygomatic arch to drain the superficial temporal space

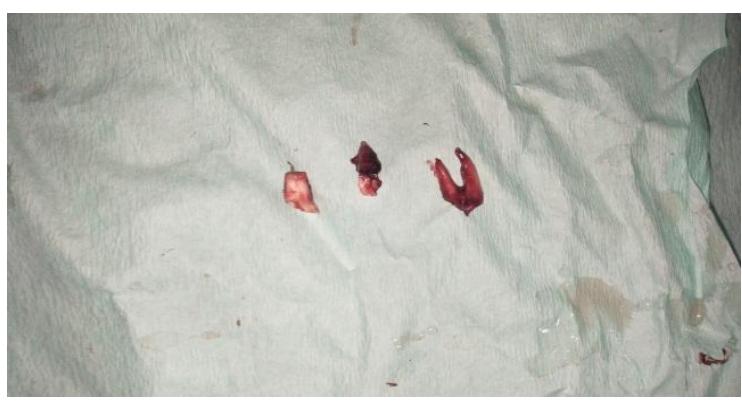

Figure 4: Extracted left maxillary second and third molar

\section{Post operative $3^{\text {rd }}$ day}

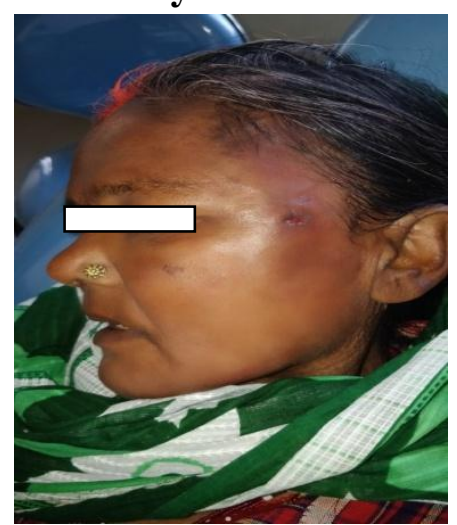

Figure 5 : Operated site

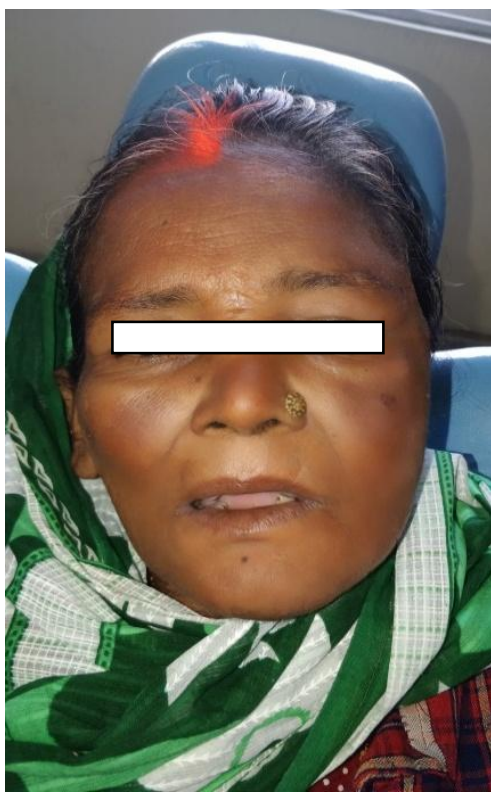

Figure 6: Increased mouth opening of patient with evident reduction in swelling of temporal and buccal regions

\section{Discussion}

In general, infectious diseases are more frequent and/or serious in patients with diabetes mellitus, which increases their morbimortality. The greater frequency of infections in diabetic patients is caused by the hyperglycaemic environment that favours immune dysfunction. In addition to the increased morbidity, infectious processes may be the first manifestation of diabetes mellitus (subscript). As in the case discussed patient was unaware of her diabetic status ${ }^{4}$.

In diabetic patients there is decreased $T$ Lymphocyte response, decreased neutrophil function, antioxidant system depression, glycosuria, lower secretion of inflammatory cytokines, hyperglycaemia which causes increased virulence of microorganism and apoptosis of PMNs all of which lead to infections.

Periodontitis is a chronic inflammatory disease characterized by the formation of a periodontal pocket, loss of connective tissue, and alveolar bone resorption, which may sometimes result in tooth loss. It is four times more common in persons with DM and is considered the sixth most common complication of $\mathrm{DM}^{5,6,7}$.

In the case discussed the patient was unaware of her diabetic status and her immune system was 
compromised due to high blood glucose level. Also it is an established fact that infections raise the blood glucose level. As during infection the body goes into stress hyperglycaemia by releasing of cortisol and glucagon which increases the blood glucose level. In the case discussed immediately after the incision and drainage and removal of the foci of infection the patient's blood glucose levels decreased to $180 \mathrm{mg} / \mathrm{dl}$.

\section{Conclusion}

Patients with TYPE 2 diabetes mellitus are at an increased risk for rapidly progressive infections. Dental management requires early identification of foci of infections and eliminating those. Patients suffering from type $2 \mathrm{DM}$ should be advised for yearly dental check-ups to avoid any complications and /or severe infections.

\section{References}

1. Oral and maxillofacial infections $4^{\text {th }}$ edition. Topaziun, Goldberg, Hupp

2. Chow AW, Roser SM, Brady FA. Orofacial odontogenic infections. Ann Intern Med 1978; 88(3): 392-02.

3. Welsh LW, Welsh JJ, Kelly JJ. Massive orofacial abscesses of dental origin. Ann Otol Rhinol Laryngol 1991; 100:768-73.

4. Juliana Casqueiro, Janine Casqueiro, and Cresio Alves Infections in patients with diabetes mellitus: A review of pathogenesis Indian J Endocrinol Metab. 2012 Mar; 16(Supp11): S27-S36. doi: $10.4103 / 2230-8210.94253$

5. Peleg AY, Weerarathna T, McCarthy JS, Davis TM. Common infections in diabetes: Pathogenesis, management and relationship to glycaemic control. Diabetes Metab Res Rev. 2007;23:3-13.

6. Alves C, Andion J, Brandão M, Menezes R. Pathogenic aspects of the periodontal disease associated to diabetes mellitus. Arq Bras Endocrinol Metab. 2007;51:10507. [PubMed]
7. Nagasawa $T$, Noda $M$, Katagiri $S$, Takaichi M, Takahashi Y, Wara-Aswapati $\mathrm{N}$, et al. Relationship between periodontitis and diabetes - importance of a clinical study to prove the vicious cycle. Intern Med. 2010;49:881-5. 